Review Article

\title{
A Review of Effects of Environmental Change on Human Health
}

\author{
Uttam Paudel \\ Department of Economics, Tribhuvan University, Kathmandu-3, Bairochan Marg, 37/7, Kathmandu, Nepal
}

Article history

Received: 08-04-2018

Revised: 24-04-2018

Accepted: 27-04-2018

Email:

uuupaude122@gmail.com uttampd112@gmail.com

\begin{abstract}
Current knowledge production on the effects of environmental exposures on human health reflects technological, social and economic development broadly; theoretical and methodological advancements in social science and medicine more specifically. Human health and the welfare mainly rely on refurbishing and protecting the integrity of the natural systems such as fresh air, safe water, biodiversity, toxic waste management and proper land reform which upkeep life in the natural environment and abating the human impact that has a negative impact on ecologically sustainable development. A massive number of scientific evidence are available in the enlightenment of environmental health issues, however, scanty literatures are found covering economically valued effects of environmental change on communicable and non-communicable diseases. Ergo, this review paper has reviewed selected papers from 1990 to 2018 and tried to identify the research gaps in effect within some components of environmental health economic issues in South Asia and Nepal. More importantly, nationally representative economic evaluation of environmental effects (air pollution, water resource management, toxic pollutants and biodiversity loss) on human infectious and non-infectious diseases are the lack for the policymakers and economic evaluation of effects of climate change on health is the unreached area of researchers in Nepal. Moreover, none of the Nepal based scientific papers are found published regarding the association of climate change with malnutrition, rate of chemical exposure to dare human health and human stress including psychosocial factors Obtaining these unreached literatures are worthy of climate policy development and implementation in developing countries associating with universal health coverage.
\end{abstract}

Keywords: Nepal, Environmental Change, Human Health, Economic Cost

\section{Introduction}

Environmental change embraces the change in the framework of natural human surroundings, which include biophysical components and processes of natural environment of land, water and air including all layers in the atmosphere, inorganic and organic matters (both living and non-living), socio-economic components and processes of the human environment mainly associated with the human health hazards. Environmental sustainability, economic efficiency and social equity provide a balancing act and sometimes compromising level of sustainable development (Oiamo, 2014).

Through the economic perspective towards environmental change, a detrimental change in environmental components i.e., environmental degradation create multiplier negative effects in the various sectors of economy of a nation, especially on health and agricultural sectors of developing economies. A study (Podesta and Ogden, 2008) suggests that while long-term environmental events, such as droughts, have no significant effect on internal migration, but sudden-onset environmental events in the form of floods significantly increase the likelihood of migration, a big international socio-economic issue. For example, approximately 600,000 people in Bangladesh and 4 million in the Philippines have been migrated because of storms, floods, droughts and landslides since the 1970s.

Environment-poverty trap can easily arise for a poor rural household with access to only marginal lands and natural resources for its own production, lack of nutritional status and the capacity for work by the poor (Barbier, 2010). On the other side, a study shows that social vulnerability increases with increase in 
environmental degradation (Luers, 2005). Poverty reduction will not necessarily lead to an improved environment unless specific environmental action is taken. A study in Pakistan argues that trade liberalization promotes environmental degradation by the export of environmental capitals (Khan et al., 2001). Public investment in environmental infrastructure should target poor households because investment in clean water and sanitation creates positive externalities for household health outcomes strongly linked to the environment in poor countries.

Environmental degradation and social injustice exert worldwide the greatest effects on the health of individuals and populations (Donohoe, 2003). Human depression caused by high salinity, asthma, suicide and heart disease with salinity can be expected to increase in rural areas in the future, further adding to the burden of disease associated with environmental degradation (Speldewinde et al., 2009; Fearnley et al., 2014). Increasing efficiency, reducing waste and properly valuing resources, will help reshape the structure of growth and reduce undesirable environmental impacts (Munasinghe, 1999).

An estimated 12.6 million deaths each year are attributable to unhealthy environments - nearly one in four of total global deaths. A bulletin of World Health Organization (WHO) has explored environmental risk factors, such as air, water and soil pollution, chemical exposures, climate change and ultraviolet radiation, contribute to more than 100 diseases and injuries (Ref. http://www.who.int/phe/en). An econometric analysis has proved that income inequality and environmental degradation have a negative and significant impact on life expectancy in Pakistan, with unidirectional causality running from environmental degradation to life expectancy (Ali and Audi, 2016).

Environmental threats to the health of children in Southeast Asia and the Western Pacific are myriad and include the classic infectious disease hazards: Pneumonia, dengue, malaria, dysentery, measles, AIDS and tuberculosis (WHO, 2017a; Zuckerman, 2012; Bonjour et al., 2013). The major environmental problems of South Asia including Nepal are degradation of air quality, drinking water, natural resources, lack of solid waste management, surface water quality, water resources, a release of toxic pollutants, loss of biodiversity, impacts of climate change and improper land use (CES, 2015).

The focus of this paper is to identify the evidence gap of environmental factors that are relatively testimony in attributing internationally to dare the human health and other economic sectors of WHO South East Asian region and others. Some potential research and review papers are selectively chosen by developing criteria for each component to ensure the idea to go in depth for a factor of environmental changes and its effects on human health. First, the papers were collected from Google Scholar,
Science Direct, PubMed and Environmental health Journals. During the selection of papers to be reviewed, criteria that the paper should directly or indirectly include all three components: environment, health and economic or econometric issues, desirably health cost; is set for the sake of finding evidence gap in Nepal and reviewed all the valued papers from 1990 to 2018 chronologically. The major components of environmental change that affect human health are reviewed based on some selected potential past pieces of evidence.

\section{Evidence on Nexus between Environmental Components and Human Health}

\section{Air Pollution and Health}

Studies at the beginning of the 1990s commonly argue that bad air pollution in cities of developing and developed countries are chronic coughing and susceptibility to infections, while deaths from air pollution occur primarily among the elderly, the infirm and the very young (Sattenspiel, 2000; Patz et al., 1996). Bronchial inflammations, allergic reactions and irritation of the mucous membranes of the eyes and nose all indicate that air pollution must be reduced (Mabahwi et al., 2015). Until 2005, WHO estimated that 2 million children under age 5 die each year from acute respiratory diseases exacerbated by air pollution (Mabahwi et al., 2015). People suffering from respiratory diseases are the most likely to be affected by air pollutions. In addition, not just air pollution can cause health effects, the study also shows that air pollution can cause stress to a human being (Mabahwi et al., 2014). WHO has economically estimated that the total health damage from air pollution (particulate matter) in China amount to $2.4-4.9 \%$ of the city's GDP; while in India, the total costs of health impacts were estimated at US\$ 113 million for a $50-\mathrm{mg} / \mathrm{m}^{3}$ increase in $\mathrm{PM}_{10}$ and US\$ 218 million for a similar increase in $\mathrm{NO}_{2}$ (WHO, 2016a).

As listed by the American Lung Association-2013, people that are at risk of particulate matter are infants, children and teens, people over 65 years old, people with lung disease (asthma, chronic pulmonary disease, chronic bronchitis and emphysema), people with heart disease or diabetes and people who work and active outdoors. Air pollution not just will harm human health but also other aspects of the environment such as visual qualities, vegetation, animals, soils and water quality (Mabahwi et al., 2014). The recent studies seem much specific towards early warning air quality daring human health (Mabahwi et al., 2015; Tin et al., 2016). Interestingly, few recent papers including review paper concluded that psychosocial factors are mainly responsible to inform public health communications used during air pollution episodes (Mabahwi et al., 2014; Tin et al., 2016; D'Antoni et al., 2017; Fuller et al., 2017; Prüss-Ustün et al., 2016; Singh et al., 2017). Regarding health cost, the indoor air pollution from 
traditional cooking energy increases chronic bronchitis, asthma and acute respiratory infections, accordingly, health cost due to dirty cooking fuel is US\$ 16.94 per rural household (Pant, 2012) and health benefit from the reduction of dirty fuel is many times higher than the cost (Pant, 2008).

\section{Drinking Water and Health}

About 2 million deaths and $15 \%$ of total child mortality in the world can be avoided by providing universal access to safe water and sanitation services, moreover, safe drinking water significantly reduces diarrheal diseases and other illnesses such as intestinal Helminth infections, Schistosomiasis and trachoma (Murty and Kumar, 2002; Prüss-Üstün et al., 2008; Gorchev and Ozolins, 2011; WHO, 2014). The burden of malaria with water management could be reduced by environmental modification and modification of human habitation by $88 \%$ (Prüss-Üstün et al., 2008), this result shows that malaria control program that emphasizes environmental management is highly effective in reducing morbidity and mortality and can lead to sustainable malaria control approaches.

The economic benefit from the drinking water resources management is estimated at $\$ 84$ billion including health care saving, averted mortality and mortality, productivity gains, time cost and others (Prüss-Üstün et al., 2008). After the publishing of WHO guidelines for safe drinking water, a study covering all WHO member countries, following a multilevel modeling approach, concluded that if the trend remains same, improved water access will not be only for $10 \%$ of the world population, making significant prevention on health hazards (Wolf et al., 2013). If water quality can be ensured up to the point-of-consumption, diarrhea can be reduced significantly by between 28 and $45 \%$, depending on the type of water supply, basically pipe water supply. Especially, in South Asia, there is a significant reduction in the occurrence of the disease through pipe supply (WHO, 2014).

A study using standardized cross-culturally valid household water insecurity scale among pregnant and HIV infected women of Kenya concluded that household water insecurity causes psychosocial impacts, economic impacts and main transmission of diseases (Krumdieck et al., 2016). Global Analysis and Assessment of Sanitation and Drinking-Water presents that though countries are showing a high level of responsiveness to the SDGs, with a majority of countries in the process of setting or planning to set targets that take into account the SDGs in the next few years; the estimated capital investment needs to reach the SDGs that are three times higher than current investment levels, significantly more resources will be required to address the financial gap and overall improving health and well-being.

For this, a country-level study addressing the possible domestic resources in the management of drinking water, a proxy of better human health from preventing water-borne diseases, seems urgent. A recent review paper with coverage since 2011 to 2015 explored that 381 new outbreak of water-borne diseases are the major cause of water knowledge and environmental degradation (Efstratiou et al., 2017). But such recent potential evidence is not found for least developed countries like Nepal.

\section{Surface Water and Health}

An old but potential study measuring economic benefit of surface water quality improvement in relation to environmental issue analysis through non-market valuation method explains that water pollution problem is not in priority of the household problem rather they are highly conscious on environmental concerns, such as deforestation and poor solid waste collection and disposal (Choe et al., 1996). Globally, 50\% of drinking water needs are fulfilled by surface water which is the main cause of transmitting diseases for far distance and $91 \%$ of the global population has an excess of improved drinking water but 159 million of these people rely on untreated surface water, which poses even greater health risks than other water sources (WHO, 2016b). As population pressures increase, the issues of water quality will become a global issue. The water cycle including wastewater and surface water needs to be managed in a holistic way to protect limited freshwater resources, for the protection of human health from waterborne infectious diseases and toxic chemicals (WHO, 2016b). But the recent studies are devoted only to ingredients presents in the surface water rather than most importantly devoting towards the source of surface water pollution leading health hazards.

\section{Solid Waste Management and Health}

A global estimation of urban solid waste presents that 4.3 billion urban residents will generate about 1.42 $\mathrm{kg} /$ capita/day of municipal solid waste by 2025 .that may have huge economic cost (Manaf et al., 2009). In developing countries, solid wastes from the hospital and chemical industries are more hazardous through the perspective of health than the general waste from households and density of waste produced in these countries is also high relative to the developed countries (Zurbrugg and Eawag, 2013). Economically sound countries are also now in the process of establishing a holistic, integrated and cost-effective solid waste management system (Manaf et al., 2009). A study undertaken in India found that excreta and other liquid and solid waste from households and the community, are a serious health hazard and lead to the spread of infectious diseases (Alam and Ahmade, 2013). Poor handling and disposal of waste are the major causes of the environmental pollution, leading to the breeding place for the pathogenic organism and spread of infectious diseases (Boadi and Kuitunen, 2005). More than $70 \%$ of the solid wastes generated in Nepal are of organic origin (Pokhrel 
and Viraraghavan, 2005), for which recently recycling coupled with composting is conceptualized to reduce the environmental impact and economic benefits in South Asian countries (Ikhlayel, 2018). Beyond this, no more papers are found addressing solid waste management and health cost burden in South Asia including Nepal.

\section{Toxic Pollutants and Health}

Health problems attributed to the presence of toxins from cyanobacteria in drinking water have been reported in a number of countries, including Australia, Brazil, China, England, South Africa and the USA (Terzopoulou and Voutsa, 2017), but later evidence claims that anthropogenic activities contribute to the spread of toxic chemicals, especially $\mathrm{Cd}, \mathrm{Hg}, \mathrm{Pb}$ and $\mathrm{As}$, into the environment, including several toxic metals and metalloids, increasing the levels of human exposure to many of them, representing a serious threat to human health. There have been identified 37 toxic organic pollutants in the crude sewage from the investigation of Chinese research which has severe and long-term impacts on environment and ecology (Jang et al., 2003; Liu et al., 2017). The study conducted in China concluded that adsorption treatment and the physicochemical-biochemical combined process seems suitable for high concentration semi coking wastewater treatment (Liu et al., 2017).

A technical study found that persistent toxic pollutants representing three classes: organo-chlorinated pesticides, polychlorinated biphenyls and polycyclic aromatic hydrocarbons are the major pollutants in water, moreover micro-pollutants such as benzanthracene, benzofluoranthene, dichlorodiphenyl dichloroethane, endosulfan II, methoxychlor and pyrene should not be neglected (Terzopoulou and Voutsa, 2017). However, any recent such technical study is not found in the context of developing countries. An economic evaluation of WHO estimated that annual illness costs of acute poisonings in Nepalese farmers due to pesticide use was nearly onethird of total annual health-care costs (WHO, 2016a). Though many pieces of evidence are available regarding health consequences, economic analysis of health consequences because of toxic organic pollutants contaminating environment are very limited and totally lack developing countries.

\section{Loss of Biodiversity and Health}

Environmental change has negatively affected most biological systems on our planet and is becoming of increasing concern for the well-being and survival of many species (Tjaden et al., 2017; MOHP, 2011). Biodiversity conservation including green space, vegetated areas, flora and fauna; creates health benefits including obesity reduction, lowered blood pressure, extended lifespan, positive impacts on mental health particularly through stress reduction and attention restoration, faster surgical recovery, patient healing and higher pain thresholds, child development through play and motor skill development, improved concentration, well-being and increased physical activity, purify the air by filtering atmospheric pollutants include nitrogen dioxide and sulphur dioxide and larger particulate matter (Davern et al., 2017).

Through the perspective of infectious diseases, there is debate among the literature regarding a negative or positive association between burdens of infectious diseases and biodiversity, rather biodiversity is different for different countries. However, a recent study with the aim to investigate the spatial and temporal relationships between Disability Adjustment Life Years (DALYs) lost to infectious disease and potential demographic, economic, environmental and biotic drivers found that countries with high biodiversity have high disease burdens, consistent with the expectation that high diversity of potential hosts should support high disease transmission (Young et al., 2017).

Moreover, urbanization and wealth were associated with lower burdens for many diseases, a pattern that could arise from increased access to sanitation and healthcare in cities and increased investment in healthcare. The importance of urbanization and wealth helps to explain why most infectious diseases have become less burdensome over the past three decades and points to possible levers for further progress in improving global public health (Ostfeld, 2017; Murray et al., 2012).

\section{Weather Events and Human Health}

Extreme weather-related mortality in the United States shows that two third of total deaths are due to excessive natural heat and remaining are due to excessive cold and others (Jiang et al., 2015). Recently it has been predicted that extreme hot weather events may cover $72 \%$ of the national population of Korea by 2090s if current trend remains same (Shim et al., 2017). Unexpected excess rainfall in Europe has made water contaminated with Arsenic and Antimony, subsequently degrading to the human health through the food chain (Cann et al., 2013). A modeling aspect of extreme weather events and human vulnerability in Europe predicts that Europe will have two third population vulnerable in terms of a climatic effect on human health by the end of this century (Forzieri et al., 2017). Similarly, heat-related weather events claimed 2248 deaths in 2015 in India (Hashim and Hashim, 2016) meaning that extreme weather events under climate change are directly or indirectly increasing the disease occurrence in South Asian countries including Nepal.

\section{Climate Change and Health}

Global warming and instability of the climate play increasingly important role in stimulating the global emergence, resurgence and transmission of infectious diseases, reported 30 new diseases and resurgence of many old diseases all over the world since 1975 (McMichael et al., 1996). Regarding evidence on climate-induced infectious diseases, biological and 
mathematical previous model to analyze the relationship between climatic change and intensity of change in infectious diseases are particularly lacking with the inclusion of non-climatic factors to dare the disease pattern change (McMichael et al., 2006). The South East Asian meet 2008 in India declared that the adaptation to inevitable effect of climate change is urgent to prevent a gigantic cost in terms of infectious diseases, health-care expenditure and lost productivity (WHO, 2009a). Scanty literatures evaluating economic impacts of climateinduced change in human health, viz. cardiovascular and respiratory disorders, diarrhea, malaria, dengue fever and schistosomiasis; have the problems with calculating Gross Domestic Product (GDP), welfare and investment fall (rise) in regions with net negative (positive) health impacts emerged by climate change and direct cost estimates; common in climate change impact studies; and underestimating the true welfare losses (Bosello et al., 2006). United States Climate Change Program presented that the impacts of climatic upsets in urban areas are likely associated increases in tropospheric ozone concentrations can contribute to or exacerbate cardiovascular and pulmonary illness and will likely be an increase in the spread of several food and water and vector-borne pathogens among susceptible populations depending on the pathogens' survival, persistence, habitat range and transmission under changing climate and environmental conditions (Forman et al., 2008). Also, the challenge posed by climate change on some new emerging diseases such as $\mathrm{HN}$ influenzas and SARs in some specific region can be reduced through strengthening local public health and medical capacity in a sustainable way (Ali et al., 2016).

Children's mental and physical health is adversely affected by forced migration and population displacement, perpetuating poverty and civil unrest in low-income and developing countries (Sheffield and Landrigan, 2011). Countries in the WHO South-East Asia Region are particularly vulnerable to a changing climate. Most recently, changes in extreme weather events, undernutrition and the spread of infectious diseases are projected to increase the number of deaths due to climate change by 2030, indicating the need to strengthen activities for adaptation and mitigation (TWB, 2010; Forzieri et al., 2017).

National action plans for climate change generally identify health as one of their priorities; however, limited information is available on implementation processes and to increase the capacity of health systems to manage the health risks of climate change in South-East Asia, if population health is to be protected and strengthened while addressing changing weather and climate patterns. Enhancing the resilience of health systems is key to ensuring a sustainable path to improved planetary and population health (Bowen and Ebi, 2017). Therefore, climate change is the major environmental factor in the emergence of new diseases, an outbreak of diseases and overall health cost burden responsible for the human being.
The major challenges for Sustainable Development Goals (SDGs) health-related indicators including 2030 agenda remain in terms of reducing maternal and child mortality, improving nutrition and achieving further progress in the battle against infectious diseases such as HIV/AIDS, tuberculosis, malaria, neglected tropical diseases, hepatitis etc. Evidence from economics based data on climate change, water and sanitation and air quality seem urgent needs to be done to reduce risks to health to recover the present major deficiencies in universal health coverage for basic health services and inadequate preparedness for health emergencies (WHO, $2017 b ; 2016 c)$. The increased frequency and intensity of extreme climatic events can cause not only injury, but also increase the risk of water-borne diseases such as diarrheal disease, Hepatitis A and E; bacterial diseases such as cholera; diseases associated with crowding (measles, meningitis, acute respiratory infections) and vector-borne diseases such as malaria, dengue as well as psychological and emotional distress related to traumatic events in WHO Southeast Asian region (WHO, 2017a; ASCI, 2009; ADB, 2008).

WHO-South East Asian environmental report has a primary focus on only environmental issues including climate change and air pollution of the countries Maldives, India and Nepal. The Maldives is comparatively less vulnerable to air pollution and solid waste management but highly affected by limited freshwater resources, heat-related illnesses, limited infectious diseases etc which are climate sensitive issues. Indian case is too vulnerable regarding air pollution, climate change, water pollution and other environmental degradation. Besides air pollution in Nepal and Bangladesh, climate change is the top challenge on health sectors where mitigation and adaptation strategy with a common program, National Adaptation Program of Action, has made ready to implement as a national plan and strategy for addressing the health risks of climate change (WHO; 2017a; 2017b; ASCI, 2009; ADB, 2008; Unit et al., 2001).

Climate change and health outcomes in South Asia is an issue that demands collaboration to develop the synergies needed to produce powerful responses (Bowen and Ebi, 2017). On the other side, Nepalese people need in improving preparedness and adaptation strategies such as coping effectively with diseases through improvement of infrastructure and facilities, assessing and educating the vulnerable section of society and enforcing regulations to protect the environment (Shrestha et al., 2017). This study mainly focuses on the review of the direct and indirect association climate change (a proxy for an environmental change) and human diseases. Therefore, this paper has thoroughly reviewed the most relevant papers summarised in Table 1 to draw the summary for the gap in the existing pieces of literature regarding climate diseases. Table 1 embraces all the relevant literatures available in different publications. 
Table 1: Evidence of climatic indicators and diseases reviewed in chronological order (covering 1990 to 2018)

\begin{tabular}{ll}
\hline Authors, Date and Country & Methods and Models \\
\hline Shope (1991), USA & Descriptive analysis
\end{tabular}

Kalkstein and Smoyer

(1993), USA

Martens et al. (1995)

Netherlands

Jetten et al. (1996),

Netherlands

Colwell (1996), Bangladesh

Martens (1998), Netherlands

Patz et al. (1998), USA

Sutherst (1998), Australia

Githeko et al. (2000), WHO

McMichael and Kovats

(2000), UK

Singh et al. (2001)

Pacific Island

Hunter (2003), UK

Gray et al. (2009), Europe

Egbendewe-Mondzozo et al.

(2011), Africa

Fox et al. (2011), UK

Lindgren et al. (2012), Europe

McIver et al. (2015),

Pacific Island

Srimath-Tirumula-Peddinti et al.

(2015), India

Hall et al. (2016), USA

Nguyen et al. (2017),

Vietnam

Stephen and Barnett (2017),

Australia

Tiwari et al. (2017), Nepal

Dhimal et al. (2017), Nepal

Temperature and Infectious Disease

Wu et al. (2009) Taiwan
Perspective Study

Synoptic climatological approach

Global modeling approach

(General Circulation Model-GCM)

Simulation Models

Logit model

Eco-epidemiologic modeling approach

General circulation model

CLIMEX approach, a spatial integrated assessment model, Descriptive regional Analysis

Descriptive Study

Poisson regression equation

Descriptive analysis

Review

Ollerenshaw index (short-term climate-driven forecast)

Descriptive analysis

Time series analyses, Poisson reg,

"likelihood vs impact" matrix

Mathematical Analysis for vector breeding dynamics

A retrospective study,

Time-series analysis

Time series analysis,

Micro-simulation models, Cost estimation, willingness to pay

Time series analysis

GIS System on climate data
Main Findings

Global warming supports the spread of dengue, yellow fever and cholera respiratory cancer, air pollution, allergic diseases, developmental effects, malnutrition and water-borne diseases. Increasing temperature increases the mortality from Onchocerciasis and malaria in USA, Canada, Egypt and China Malaria and schistosomiasis transmission are significantly increased in higher altitude and less economically developed areas due to temperature and rainfall change.

Dynamic vectorial capacity model for malaria prediction which predicts that malaria cases significantly increases with a $2-4^{\circ} \mathrm{C}$ temperature increase.

The positive association between Sea surface temperature and cholera outbreak.

Increase in temperature increases the vector-borne diseases (VBD) and deteriorates agriculture, vegetation and migration $1.16^{\circ} \mathrm{C}$ temperature increase by 2050 in temperate regions will have $47 \%$ higher risk of dengue.

CLIMAX is the best tool for the analysis of VBD and climate risks.

El'Nino temperature up by $1-3.5^{\circ} \mathrm{C}$ by 2100 will encourage the outbreaks of vector-borne diseases in all regions increasing the cost of treatment.

Biological, behavioral and social modes of adaptation strategy are most for the reduction of climatic vulnerability.

A positive association between annual average temperature and the rate of diarrhea reports and a negative association between water availability and diarrhea rates

Heavy rainfall and increased temperature cause high risk of infectious diseases due to drinking water.

Climate suitability models predict that eight important tickborne diseases are likely to establish more northern permanent populations in a climate-warming scenario.

Semi-parametric econometric model Increased malaria due to the marginal change in temperature and precipitation by the end of the century, increases $20 \%$ high-cost burden.

Fasciola hepatica (liver fluke), a physically and economically devastating parasitic trematode, rising is due to climate change. Climate change, travel, migration and global trade are the major cause of transmission of diseases such as chikungunya fever, dengue fever and other emerging infectious diseases in Europe The vulnerability is a function of individual country's unique geographic, demographic and socioeconomic characteristics combined with changing weather patterns, climate change. Correlation analysis, linear and multiple regression analysis multiple regression and ARIMA models are best-suited models for modeling and prediction of disease incidences and mosquito population.

Need for continued surveillance of climate-induced changes to migratory behavior and vector activity to predict pathogen prevalence.

$1{ }^{\circ} \mathrm{C}$ increase in average temperature and $1 \%$ increase in humidity is associated with $5.6 \%$ and $1.7 \%$ increase in hand, foot and mouth disease rate respectively.

Estimated costs of salmonellosis increased from 456.0 QALYs and AUD 29,900,000 million, assuming no climate change, to 485.9 QALYs and AUD 31,900,000 under the climate change scenario

Rainfall shocks experienced early in life contribute to child growth faltering, but that the damage is transitory, with no discernible scars by age 5

Vector-borne diseases, diarrheal diseases including cholera, malnutrition, cardiorespiratory diseases, psychological stress and health effects and injuries related to extreme weather are major climate-sensitive health risks in Nepal.

Every $1^{\circ} \mathrm{C}$ increase in monthly average temperature increases the total population at risk for dengue fever by 1.95 times. 
Table 1: Continue

\begin{tabular}{ll}
\hline Hajat et al. (2014), UK & $\begin{array}{l}\text { Time series regression model, } \\
\text { epidemiological analysis }\end{array}$ \\
Jagai et al. (2017), USA & $\begin{array}{l}\text { Multi-level linear regression } \\
\text { models, age-adjusted mean }\end{array}$ \\
Liang and Gong (2017) & Review of evidence
\end{tabular}

Rainfall and Infectious Diseases Curriero et al. (2001), USA

Nichols et al. (2009), UK

Drayna et al. (2010), USA

Chen et al. (2012), Taiwan

Wiwanitkit and Wiwanitkit

(2013), Thailand

Chien and Yu (2014),

Taiwan

Ahmad et al. (2015),

Pakistan

Abiodun et al. (2016),

South Africa

Kulinkina et al. (2016),

India

Phung et al. (2016),

Vietnam

Extreme Weather Events and Diseases Occurrence

Greenough et al. (2001), USA

Descriptive Study

Wu et al. (2007), Taiwan

Autoregressive integrated

moving average models

Gullón et al. (2017), Spain

Mixed-Effects Poisson regression

Kjellstrom et al. (2017)

Descriptive study

Climate Change, Vulnerability and Adaptation/Mitigation

IPCC (2007a), South Asia Descriptive Study

Gamble et al. (2008), USA Descriptive study

Hijioka et al. (2014), Asia

Descriptive Study

Oppenheimer et al. (2015)

Descriptive Study

Aslam et al. (2017),

Pakistan
Bottom-up approaches,

Poisson dist.
Heat-related deaths would be expected to rise by around $257 \%$

by the 2050 s, cold-related mortality would decline by $2 \%$ for

absence of adaptation in the population

A one-degree Celsius increase in maximum monthly average

temperature is associated with a 0.34 increase in Heat-stress

Illness in highly urbanized counties.

Geographically, regions experiencing higher temperature anomalies have been given more research attention; unfortunately, the Earth's most vulnerable regions to climate variability and extreme events have been less studied.

Fifty-one percent of waterborne disease outbreaks associated with precipitation events above the 90 th percentile and $68 \%$ by events above the 80th percentile.

Low rainfall and heavy rain precede many drinking water-borne diseases outbreaks

Any rainfall 4 days prior was significantly associated with an $11 \%$ increase in Acute Gastrointestinal Illnesses visits in a major U.S. metropolitan area

Precipitation $(350 \mathrm{~mm} /$ day $)$ can result in the highest relative risk for bacillary dysentery and enterovirus infections and vectorborne diseases such as dengue fever and Japanese encephalitis. A derived least square equation Chikungunya prevalence $(\mathrm{Y})$ versus rainfall $(X)$ is found $Y=0.8 X+0.6(r=0.54, p<0.05)$. High nonlinearity of temporal lagged effects and magnitudes of temperature and rainfall on dengue fever epidemics.

Temporal variation of malaria cases is positively associated with the meteorological variables including average monthly rainfall, water supply and sewage system and solid waste collection.

A potential model derivation to quantify the seasonality of the population, vector population dynamics and to predict $A n$. arabiensis population dynamics.

Higher ambient temperature decreased and higher rainfall increased diarrheal risk with the temperature being the predominant factor in urban and rainfall in rural sites Levels of infectious intestinal diseases following a heavy rainfall event increase from 7.3 to $13.5 \%$ for lags from 0 to 21 days.

Extreme weather events such as precipitation extremes, El'Nino and severe storms caused hundreds of deaths and injuries annually in the United States.

Weather variability is a significant indicator of the increasing occurrence of dengue fever.

There is an increased risk of Hepatitis A 2 weeks after water-related climate events.

Occupational health is particularly affected by high heat exposures in workplaces, which will be an increasing problem by the end of this century in South Asian Region (Nepal, Maldives, India and Bangladesh).

By 2050, freshwater in South Asia is projected to decrease; heavily populated regions will be at greatest risk due to increased flooding leading high economic cost due to diarrheal disease.

Vulnerabilities are shaped not only by existing climatic exposures, sensitivities and adaptive capacities but also by responses to risks.

Increases in heavy rain and temperature will increase the risk of diarrheal diseases, dengue fever and malaria in South Asia.

Vulnerability and key climate change risks in light of criteria are found as risk of death, injury, ill-health, coastal flooding and sea level rise.

Cumulative loss projected for frequent floods without adaptation will be in the range of USD 66.8-79.3 billion in the time lapse of 40 years from 2010 . 


\begin{tabular}{|c|c|c|}
\hline \multicolumn{3}{|l|}{ Evidence from Nepal } \\
\hline Bhandari et al. (2012), Nepal & Time series analysis & $\begin{array}{l}\text { There is statistically significant correlation between diarrheal } \\
\text { cases occurrence and temperature and rainfall. }\end{array}$ \\
\hline Dhimal et al. (2014), Nepal & $\begin{array}{l}\text { Cross-sectional Study, } \\
\text { Hotpot analysis }\end{array}$ & $\begin{array}{l}1^{\circ} \mathrm{C} \text { increase in minimum and mean temperatures increase } \\
\text { malaria incidence by } 27 \text { and } 25 \% \text { respectively. }\end{array}$ \\
\hline Dhimal et al. (2015), Nepal & Cross-sectional study & $\begin{array}{l}\text { Climatic variables; rainfall, temperature and relative humidity } \\
\text { seem significant predictors of chikungunya and dengue virus } \\
\text { vectors abundance. }\end{array}$ \\
\hline Dhital et al. (2016), Nepal & Review study & $\begin{array}{l}\text { Direct and indirect climatic effect on health could be expected } \\
\text { further enhanced with social and environmental differences } \\
\text { within the country. }\end{array}$ \\
\hline Pant et al. (2017), Nepal & Descriptive and spatial analysis & $\begin{array}{l}\text { There is a strong clustering of Japanese Encephalitis incidence } \\
\text { in monsoon season in the south-western and south-eastern } \\
\text { Terai region of Nepal }\end{array}$ \\
\hline \multicolumn{3}{|c|}{ Cost Burdens of Climate-sensitive Diseases and Outcomes } \\
\hline Tol (2002) & $\begin{array}{l}\text { GCM based Model, } \\
\text { Meta-analytical methods }\end{array}$ & $\begin{array}{l}\text { Globally, a } 1{ }^{\circ} \mathrm{C} \text { warming would be a positive } 2 \% \text { of gross world } \\
\text { product, with a standard deviation of } 1 \% \text { including health cost. }\end{array}$ \\
\hline IPCC (2007b) & Top-down modeling & $\begin{array}{l}\text { Global modeled climate costs are sensitive with some regions, } \\
\text { sectors (e.g., land-use), use of revenues from carbon taxes and } \\
\text { auctioned permits, co-benefits of mitigation measures, } \\
\text { or equity issues. }\end{array}$ \\
\hline Ebi (2008) & Predictive cost estimation & $\begin{array}{l}\text { At } 750 \text { ppm CO } 2 \text { emission, the costs of treating diarrheal } \\
\text { diseases, malnutrition and malaria in } 2030 \text { is estimated to be } \$ 4 \\
\text { to } 12 \text { billion worldwide. }\end{array}$ \\
\hline UNFCCC, 2009 & Review study & $\begin{array}{l}\text { Costs of adaptation through an aggregate level analysis and } \\
\text { disaggregated approach provides better estimates at the sectoral } \\
\text { level, but faces considerable uncertainty. }\end{array}$ \\
\hline WHO (2009b) & Descriptive analysis & $\begin{array}{l}\text { A need for cost-effectiveness of interventions to protect health } \\
\text { from climate change and monetized health benefits is higher } \\
\text { than mitigation costs. }\end{array}$ \\
\hline Hutton (2011) & Review study & $\begin{array}{l}\text { Global adaptation cost studies carried out so far indicate health } \\
\text { sector costs of roughly US\$2-5 billion annually. }\end{array}$ \\
\hline Yoon et al. (2014) & $\begin{array}{l}\text { Disability-adjusted life } \\
\text { years (DALY) }\end{array}$ & $\begin{array}{l}\text { Cerebrovascular diseases caused by heat waves accounted for } \\
72.1 \% \text { of the total burden of disease (in DALYs) in } \\
\text { South Korea. }\end{array}$ \\
\hline McDonald et al. (2015) & Climate health justice model & $\begin{array}{l}\text { Asthma, ischemic heart disease, diarrhea and heat } \\
\text { exhaustion/cramps/stroke/syncope charges amounted to } \\
\text { US } \$ 5.6 \text { billion in } 2008 \text { to } 2010 \text {. }\end{array}$ \\
\hline Hsiang et al. (2017), USA & $\begin{array}{l}\text { Spatial empirical adaptive } \\
\text { assessment system }\end{array}$ & $\begin{array}{l}\text { The total value of market and nonmarket damage due to global } \\
\text { mean temperature costs roughly } 1.2 \% \text { of gross domestic product } \\
\text { per }+1^{\circ} \mathrm{C} \text { on average. }\end{array}$ \\
\hline
\end{tabular}

First, the literatures are systematically managed and reviewed chronologically as per the relevancy of the climate disease relationship, then the literatures specific to certain climatic components and their effects on health are reviewed, and finally the papers based on climatic vulnerability, adaptation and the cost burden raised by climatic hazards are adequately reviewed covering international to local potential publications and reports.

Improved economic assessments associated with the health cost of climate change can be essential in health adaptation programs and support mitigation policies that enhance health. Economic evaluations of mitigation policies could explore the major health co-benefits, covering much of the cost of the initial investment. But special methods particularly on how best to represent uncertainty, the relative value of future benefits (e.g., discounting) and the achievement of equity is quite difficult. If these methods applied to assess the health costs of inaction on climate change, the costs and benefits of investing in health adaptation, at the global, regional or local level, as well as of mitigation actions impacting on health would be more accurate. But the country-based papers till the date are limited to find the partial cost of whole damage made by climatic hazards.

\section{Conclusion and Evidence Gap}

Environmental degradation causes multiple negative multiplier effects leading unstable global health situation. As referring to a truncated review of the major environmental factors, in fact, helped to identify the present daring major factor to human health, especially increasing future and present health cost by promoting regular new disease occurrence. From the review of past evidence, an association of air pollution with human stress and economic cost of stress, a recent matter of medical discussion, is one of the potential research gaps in south Asia. None of the paper is found finding a social burden in terms of cost due to water-borne diseases. Similarly, effects of climate change on toxic pollutants which have indirect health consequences is also an 
unreached area of researchers in the context of Nepal. Solid waste management in the South Asian region are major challenges for the prevalence of new diseases, but the pieces of evidence are devoted only to exploring challenges rather than cost-effective management scenarios. Air pollution could be controlled by the human, but climate change might be inevitable to cause several diseases and other vulnerability or hazards. Therefore, climate change is the major component of the environmental changing factor to be studied economically in relation to the human health where the community is most vulnerable or sensitive to climate change.

Extreme weather events under climate change in terms in temperature, humidity and rainfall has been increasing health vulnerability and claiming the human life and other morbidities in South Asia including Nepal, though there is not found any recent potential research to build research-based effective adaptation and mitigation action plan implementation in Nepal. Almost all the scientific studies from 1990 to 2000 are found based on the descriptive methods in the explanation of climatehealth relationship. Few papers addressed some predictions over the climate risk assessment daring human diseases by 2050. Similarly, the studies from 2001 to 2010 are found quite extended in the response of global to local climate change issues daring human health from several dimensions. And the recent papers from 2011 to the date are devoted to exploring the sensitivity of climatic variability towards communicable and non-communicable diseases.

While reviewing the methodological sections of the entire evidence, a deficiency on the geographical databased study including social, economic, climatic, ecological factors as well as human immunity, undernutrition, physical infectious diseases and mental health is found. More specifically, vector-borne diseases, foodborne diseases and water-borne diseases are most sensitive to heat stress and rainfall in South Asia. Therefore, as other studies, this study also concludes with a need of advanced ecological niche modeling, entomological surveillance, early warning system and country-wise spatial and temporal scales economic evaluation based studies including socioeconomic factors to be adopted in the analysis of future studies.

Regarding temperature-diseases relationship, almost all the papers seemed devoted to finding the present association and future consequences of heat-related temperature change towards the increase and outbreaks of many infectious diseases such as malaria, dengue, cholera and few other diseases related mortality. Similarly, rainfall and precipitation are associated with waterborne diseases and drinking water-related diseases. But few studies have recommended for multivariate analysis including climatic and non-climatic factors may yield the robust result to the policymakers. However, all the papers are with the lack of proper recommendation for future consequences of diseases due to extreme rainfall. It is suggested that eco-climatic condition, geographical condition, water supply, sewage system, solid waste collection and appropriate adaptation strategy are to be addressed. Regarding weather extreme and infectious diseases, El'Nino oscillation is the major for human diseases such as Hepatitis A, malaria, dengue and other infectious and non-infectious diseases are highly sensitive to extreme weather events. Variations of socio-ecological changes, diseases transmission patterns, disaster resilience programs, early warning capabilities, cultural practices etc are the major issues to be taken into account while protecting health from extreme weather events.

South Asia based studies provides the evidence gap that all the south Asian countries should conduct country-wise national analytical and multi-dynamic research including climatic and non-climatic indicators through economic perspective for the generation of selfmotivation in the country to local level, especially aquaculture productivity, reduced physical work, flood, heat waves, draughts, under-nutrition, mental health, infectious disease etc. in the short run and food security, water shortage, flood related injuries, diseases, mental disorders etc. are to be addressed while studying health consequences of climate change in the long run. In Nepal, vector-borne diseases- Chikungunya malaria, dengue, Japanese Encephalitis; water-borne diseasesbacillary diarrheal disease including cholera; foodborne diseases, malnutrition, cardiorespiratory diseases, psychological stress and health effects and injuries related to extreme weather are major climate-sensitive health risks whose prospective longitudinal study with the inclusion of economic evaluation on climatic effect over health seems an urgent need for the development of climate adaptation policy and health system management accordingly in the country.

Climate change influences human health in various ways and quantitative assessments of the effect of climate change on health at the national level are becoming essential for environmental health management. The evidence is seemed devoted to finding the climate caused heath cost partially as the damage costs, but these evaluations of costs cover the fraction of the total societal cost. Economic evaluation of adaptation cost is, therefore, seemed urgent to inform the policymakers in the formulation of better health perspective associated with climatic hazards. Global assessment of the cost of climate change is measured in terms of GDP or welfare or investment. Less than ten scientific pieces of evidence are found in the estimation of health cost of climate change by employing sum methods and spatial empirical adaptive global-to-local assessment system, only being based on the developed country database. Therefore, beyond past myopic evidence, an integrated country-wise south Asian level study using multivariate analysis to find the 
relationship between environmental change and diseases incidence including socioeconomic and household behavioral factors is seemed urgent to reduce the current climatic vulnerability encouraging unknown outbreaks of emerging and re-emerging diseases; and private public health cost burden.

\section{Funding Information}

This review paper has prepared without any external funding source.

\section{Acknowledgement}

Author acknowledges comments and suggestions for Dr. Shiva Raj Adhikari, PhD Supervisor; Dr. Krishna Prasad Pant, PhD Co-supervisor; Umesh Khatri, Co-worker in Research and University Grants Commission Nepal.

\section{Conflict of Interest}

Author declares that there is no any conflict of interest.

\section{References}

Abiodun, G.J., R. Maharaj, P. Witbooi and K.O. Okosun, 2016. Modelling the influence of temperature and rainfall on the population dynamics of Anopheles arabiensis. Malaria J., 15: 1-15.

DOI: $10.1186 / \mathrm{s} 12936-016-1411-6$

ADB, 2008. Islamic Republic of Pakistan Country Environment Analysis. Production, Asian Development Bank.

Ahmad, S.S., N. Aziz and A. Butt, 2015. Spatio-temporal surveillance of water based infectious disease (malaria) in Rawalpindi, Pakistan using geostatistical modeling techniques.

Alam, P. and K. Ahmade, 2013. Impact of solid waste on health and the environment. Int. J. Sustain Dev., 2013: 165-168.

Ali, A. and M. Audi, 2016. The impact of income inequality, environmental degradation and globalization on life expectancy in Pakistan: An empirical analysis. MPRA Pap No 71112.

Ali, H., B. Dumbuya, M. Hynie, P. Idahosa and R. Keil, 2016. Climate Change and Health. In: Improving Resilience and Reducing Risks, Filho, W.L., U.M. Azeiteiro and F. Alves (Eds.), Springer International Publishing, ISBN-10: 978-3-319-24658-1, pp: 151-69.

Analysis, U.G., 2017. Financing universal water, sanitation and hygiene under the sustainable development goals.

ASCI, 2009. Leadership through learning. Anal. Exist Environ. Instruments India.
Aslam, A.Q., S.R. Ahmad, I. Ahmad, Y. Hussain and M.S. Hussain, 2017. Vulnerability and impact assessment of extreme climatic event: A case study of southern Punjab, Pakistan. Sci. Total Environ., 580: 468-481. DOI: 10.1016/j.scitotenv.2016.11.155

Barbier, E.B., 2010. Poverty, development and environment. Environ. Dev. Econ., 15: 635-660. DOI: $10.1017 / \mathrm{S} 1355770 \mathrm{X} 1000032 \mathrm{X}$

Bhandari, G.P., S. Gurung, M. Dhimal and C.L. Bhusal, 2012. Climate change and occurrence of diarrheal diseases: evolving facts from Nepal. J. Nepal Health Res. Counc., 10: 181-186.

Boadi, K.O. and M. Kuitunen, 2005. Environmental and health impacts of household solid waste handling and disposal practices in third world cities: the case of the Accra Metropolitan Area, Ghana. J. Environ. Health, 68: 32-36. PMID: 16334095

Bonjour, S., H. Adair-Rohani, J. Wolf, N.G. Bruce and S. Mehta et al., 2013. Solid Fuel Use for Household Cooking: Country and Regional Estimates for 1980-2010. Environ. Health Perspect., 784: 784-790. DOI: $10.1289 /$ ehp. 1205987

Bosello, F., R. Roson and R.S.J. Tol, 2006. Economywide estimates of the implications of climate change: Human health. Ecol. Econ., 58: 579-591. DOI: $10.1016 /$ j.ecolecon.2005.07.032

Bowen, K.J. and K.L. Ebi, 2017. Health risks of climate change in the World Health Organization South-East Asia Region.

Cann, K.F., D.R. Thomas, R.L. Salmon, A.P. Wyn-Jones and D. Kay, 2013. Extreme water-related weather events and waterborne disease. Epidemiol. Infect., 141: 671-686. DOI: 10.1017/S0950268812001653

CES, 2015. Of C. environment statistics.

Chen, S., C. Liao, C. Chio, H. Chou and S. You et al., 2010. Science of the Total Environment Lagged temperature effect with mosquito transmission potential explains dengue variability in southern Taiwan: Insights from a statistical analysis. Sci. Total Environ., 408: 4069-4075. DOI: $10.1016 /$ j.scitotenv.2010.05.021

Chien, L. and $\mathrm{H}$. $\mathrm{Yu}, 2014$. Impact of meteorological factors on the spatiotemporal patterns of dengue fever incidence. Environ. Int., 73: 46-56. DOI: $10.1016 /$ j.envint.2014.06.018

Choe, K., D. Whittington and D.T. Lauria, 1996. The economic benefits of surface water quality improvements in developing countries: A case study of Davao, Philippine. Land Econ., 72: 519-537. DOI: $10.2307 / 3146913$

Colwell, R.R., 1996. Global climate change and infectious diseases: the cholera paradigm. Science, 274: 2025-2031. 
Curriero, F.C., J.A. Patz, J.B. Rose and S. Lele, 2001. The association between extreme precipitation and waterborne disease outbreaks in the United States, 1948-1994. 91: 1194-1199.

D'Antoni, D., L. Smith, V. Auyeung and J. Weinman, 2017. Psychosocial and demographic predictors of adherence and non-adherence to health advice accompanying air quality warning systems: A systematic review. Environ. Health, 16: 1-18.

DOI: $10.1186 / \mathrm{s} 12940-017-0307-4$

Davern, M., A. Farrar, D. Kendal and B. Giles-corti, 2017. Quality green space supporting health, wellbeing and biodiversity: A literature review.

Dhimal, M., I. Gautam, H.D. Joshi, R.B. O'Hara and B. Ahrens et al., 2015. Risk factors for the presence of chikungunya and dengue vectors (Aedes aegypti and Aedes albopictus), their altitudinal distribution and climatic determinants of their abundance in central Nepal. PLoS Negl. Trop. Dis., 9: 1-20.

DOI: 10.1371/journal.pntd.0003545

Dhimal, M., M.L. Dhimal, R.R. Pote-Shrestha, D.A. Groneberg and U. Kuch, 2017. Health-sector responses to address the impacts of climate change in Nepal. WHO South-East Asia J. Public. Health, 6: 9-14. DOI: 10.4103/2224-3151.213795

Dhimal, M., R.B. O'Hara, R. Karki, G.D. Thakur and U. Kuch et al., 2014. Spatio-temporal distribution of malaria and its association with climatic factors and vector-control interventions in two high-risk districts of Nepal. Malaria J., 13: 1-14.

DOI: $10.1186 / 1475-2875-13-457$

Dhital, S.R., M. Koirala, S. Dhungel and G. Gulis, 2016. Climate change and its impacts on human health in Nepal. J Health Educ. Res. Dev.,4: 4-7. DOI: $10.4172 / 2380-5439.1000174$

Donohoe, M., 2003. Causes and health consequences of environmental degradation and social injustice. Soc. Sci. Med., 56: 573-587. DOI: $10.1016 / \mathrm{S} 0277-9536(02) 00055-2$

Drayna, P., S.L. Mclellan, P. Simpson, S. Li and M.H. Gorelick, 2010. Research | Children's health association between rainfall and pediatric emergency department visits. 118: 1439-1443.

Ebi, K.L., 2008. Adaptation costs for climate changerelated cases of diarrhoeal disease, malnutrition and malaria in 2030. Global Health, 4: 1-9.

DOI: $10.1186 / 1744-8603-4-9$

Efstratiou, A., J.E. Ongerth and P. Karanis, 2017. Waterborne transmission of protozoan parasites: Review of worldwide outbreaks - An update 2011-2016. Water Res., 114: 14-22.

DOI: $10.1016 /$ j.watres.2017.01.036

Egbendewe-Mondzozo, A., M. Musumba, B.A. McCarl and $\mathrm{X}$. Wu, 2011. Climate change and vector-borne diseases: An economic impact analysis of malaria in Africa. Int. J. Environ. Res. Public. Health, 8: 913-930. DOI: 10.3390/ijerph8030913
Fearnley, E.J., R.J.S. Magalhães, P. Speldewinde, P. Weinstein and A. Dobson, 2014. Environmental correlates of mental health measures for women in Western Australia. Ecohealth, 11: 502-511. DOI: $10.1007 / \mathrm{s} 10393-014-0966-3$

Forman, S., N. Hungerford, M. Yamakawa, T. Yanase and H.J. Tsai et al., 2008. Climate change impacts and risks for animal health in Asia. Rev. Sci. Technol., 27: 581-597. DOI: 10.20506/rst.27.2.1814

Forzieri, G., A. Cescatti, F.B. Silva and L. Feyen, 2017. Increasing risk over time of weather-related hazards to the European population: a data-driven prognostic study. Lancet Planet Health, 1: e200e208.

Fox, N.J., P.C.L. White, C.J. McClean, G. Marion and A. Evans et al., 2011. Predicting impacts of climate change on fasciola hepatica risk. PLoS One, 6: 19-21. DOI: 10.1371 /journal.pone.0016126

Fuller, C.H., K.R. Feeser, J.A. Sarnat and M.S. O'Neill, 2017. Air pollution, cardiovascular endpoints and susceptibility by stress and material resources: a systematic review of the evidence. Environ. Health, 16: 1-17. DOI: 10.1186/s12940-017-0270-0

Gamble, J.L., K.L. Ebi, A.E. Grambsch, F.G. Sussman and T.J. Wilbanks, 2008. Analyses of the effects of global change on human health and welfare and human systems.

Githeko, A.K., S.W. Lindsay, U.E. Confalonieri and J.A. Patz, 2000. Climate change and vector-borne diseases: A regional analysis. Bull. World Health Organ., 78: 1136-1147.

Gorchev, H.G. and G. Ozolins, 2011. WHO guidelines for drinking-water quality. WHO Chron., 38: 104-108.

Gray, J.S., H. Dautel, A. Estrada-Peña, O. Kahl and E. Lindgren, 2009. Effects of climate change on ticks and tick-borne diseases in Europe. Interdiscip. Perspect. Infect. Dis., 2009: 1-12.

Greenough, G., M. McGeehin, S.M. Bernard, J. Trtanj and J. Riad et al., 2001. The potential impacts of climate variability and change on health impacts of extreme weather events in the United States. Environ. Health Perspect., 109: 191-198.

Gullón, P., C. Varela, E.V. Martínez and D. GómezBarroso, 2017. Association between meteorological factors and hepatitis A in Spain 2010-2014. Environ. Int., 102: 230-235. DOI: 10.1016/j.envint.2017.03.008

Hajat, S., S. Vardoulakis, C. Heaviside and B. Eggen, 2014. Climate change effects on human health: Projections of temperature-related mortality for the UK during the 2020s, 2050s and 2080s. J. Epidemiol. Community Health, 68: 641-648.

Hall, R.J., L.M. Brown and S. Altizer, 2016. Modeling vector-borne disease risk in migratory animals under climate change. Integr. Comput. Biol., 56: 353-364. DOI: $10.1093 / \mathrm{icb} / \mathrm{icw} 049$

Hashim, J.H. and Z. Hashim, 2016. Climate change, extreme weather events and human health implications in the Asia pacific region. Asia Pacific J. Public. Health, 28: 8S-14S. 
Hijioka, Y., E. Lin, J.J. Pereira, R.T. Corlett and X. Cui et al., 2014. Asia. Clim Change 2014 Impacts, Adapt Vulnerability Part B Reg Asp Contrib Work Gr II to Fifth Assess Rep Intergov Panel Clim Chang.

Hsiang, S., M. Delgado, S. Mohan, D.J. Rasmussen and R. Muir-Wood et al., 2017. Estimating economic damage from climate change in the United States. Science, 356: 1362-1369. DOI: $10.1126 /$ science.aal4369

Hunter, P.R., 2003. Climate change and waterborne and vector-borne disease. J. Applied Microbiol. 94: 37-46. DOI: 10.1046/j.1365-2672.94.s1.5.x

Hutton, G., 2011. The economics of health and climate change: key evidence for decision making. Global Health, 7: 18-18. DOI: 10.1186/1744-8603-7-18

Ikhlayel, M., 2018. Development of management systems for sustainable municipal solid waste in developing countries: A systematic life cycle thinking approach. J. Cleaner Product. 180: 571-586. DOI: $10.1016 /$ j.jclepro.2018.01.057

IPCC, 2007a. Climate Change 2007 Synthesis Report. 1st Edn.,Intergovernmental Panel on Climate Change, pp: 104.

IPCC, 2007b. Mitigation of Climate Change: Contribution of Working Group III to the Fourth Assessment Report of the Intergovernmental Panel on Climate Change. 1st Edn., Intergovernmental Panel on Climate Change, pp: 851.

Jagai, J.S., E. Grossman, L. Navon, A. Sambanis and S. Dorevitch, 2017. Hospitalizations for heat-stress illness varies between rural and urban areas: An analysis of Illinois data, 1987-2014. Environ. Health A Glob Access. Sci. Source, 16: 1-10.

DOI: $10.1186 / \mathrm{s} 12940-017-0245-1$

Jang, M.H., K. Ha, G.J. Joo and N. Takamura, 2003. Toxin production of cyanobacteria is increased by exposure to zooplankton. Freshwater Biol., 48: 1540-1550.

Jetten, T.H., W.J.M. Martens and W. Takken, 1996. Model simulations to estimate malaria risk under climate change. J. Med. Entomol., 33: 361-371. DOI: $10.1093 /$ jmedent/33.3.361

Jiang, C., K.S. Shaw, C.R. Upperman, D. Blythe and C. Mitchell et al., 2015. Climate change, extreme events and increased risk of salmonellosis in Maryland, USA: Evidence for coastal vulnerability. Environ. Int., 83: 58-62.

DOI: $10.1016 /$ j.envint.2015.06.006

Kalkstein, L.S. and K.E. Smoyer, 1993. The impact of climate change on human health: Some international implications. Experientia, 49: 969-979.

DOI: 10.1007/BF02125644

Khan, S.R., M.A. Khwaja and A.M. Khan, 2001. Environmental impacts and mitigation costs associated with cloth and leather exports from Pakistan. Environ. Dev. Econ., 6: 383-403. DOI: $10.1017 / \mathrm{S} 1355770 \mathrm{X} 01000213$
Kjellstrom, T., B. Lemke and M. Otto, 2017. Climate conditions, workplace heat and occupational health in South-East Asia in the context of climate change. 6: $15-21$.

Krumdieck, N.R., S.M. Collins, P. Wekesa, P. Mbullo and G.O. Boateng et al., 2016. Household water insecurity is associated with a range of negative consequences among pregnant Kenyan women of mixed HIV status. J. Water Health, 14: 1028-1031. DOI: $10.2166 /$ wh.2016.079

Kulinkina, A.V., V.R. Mohan, M.R. Francis, D. Kattula and R. Sarkar et al., 2016. Seasonality of water quality and diarrheal disease counts in urban and rural settings in south India. Nat. Public., 2016: 1-12. DOI: $10.1038 /$ srep20521

Liang, L. and P. Gong, 2017. Climate change and human infectious diseases: A synthesis of research findings from global and spatio-temporal perspectives. Environ. Int., 103: 99-108. DOI: 10.1016/j.envint.2017.03.011

Lindgren, E., Y,. Andersson J.E. Suk, B. Sudre and J.C. Semenza, 2012. Monitoring EU emerging infectious disease risk due to climate change. Science, 336: 418-419.

Liu, Y., J. Liu, A. Zhang and Z. Liu, 2017. Treatment effects and genotoxicity relevance of the toxic organic pollutants in semi-coking wastewater by combined treatment process. Environ. Pollut., 220: 13-19. DOI: 10.1016/j.envpol.2016.04.095

Luers, A.L., 2005. The surface of vulnerability: An analytical framework for examining environmental change. Global Environ. Change, 15: 214-223. DOI: 10.1016/j.gloenvcha.2005.04.003

Mabahwi, N.A., O.L.H. Leh and D. Omar, 2015. Urban air quality and human health effects in Selangor, Malaysia. Proc. Soc. Behav. Sci., 170: 282-291. DOI: 10.1016/j.sbspro.2015.01.038

Mabahwi, N.A.B., O.L.H. Leh and D. Omar, 2014. Human health and wellbeing: Human health effect of air pollution. Proc. Soc. Behav. Sci., 153: 221-229. DOI: 10.1016/j.sbspro.2014.10.056

Manaf, L.A., M.A.A. Samah and N.I.M. Zukki, 2009. Municipal solid waste management in Malaysia: Practices and challenges. Waste Manage., 29: 2902-2906. DOI: 10.1016/j.wasman.2008.07.015

Martens, W.J., 1998. Health impacts of climate change and ozone depletion: An ecoepidemiologic modeling approach. Environ. Health Perspect., 106: 241-251. DOI: 10.2307/3433924

Martens, W.J.M., T.H. Jetten, J. Rotmans and L.W. Niessen, 1995. Climate change and vectorborne diseases: A global modelling perspective. Global Environ. Change, 5: 195-209. DOI: 10.1016/0959-3780(95)00051-O 
McDonald, Y.J., S.E. Grineski, T.W. Collins and Y.A. Kim, 2015. A scalable climate health justice assessment model. Soc. Sci. Med., 133: 242-252. DOI: 10.1016/j.socscimed.2014.10.032

McIver, L., R. Kim, A. Woodward, S. Hales and J. Spickett et al., 2015. Health impacts of climate change in pacific island countries: A regional assessment of vulnerabilities and adaptation priorities. Environ. Health Perspect., 124: 31-31.

Mcmichael, A.J. and K.R. Sari, 2000. Climate change and climate variability: Adaptations to reduce adverse health impacts. Environ. Monitor. Assess., 61: 49-64. DOI: 10.1023/A:1006357800521

McMichael, A.J., Haines and K. Slooff, 1996. Climate change and human health. World Health Organization.

McMichael, A.J., R.E. Woodruff and S. Hales, 2006. Climate change and human health: Present and future risks. Lancet, 367: 859-869. DOI: $10.1016 / \mathrm{S} 0140-6736(06) 68079-3$

MOHP, 2011. Nepal Demographic and Health Survey 2011. Ministry of Health and Population.

Munasinghe, M., 1999. Is environmental degradation an inevitable consequence of economic growth: Tunneling through the environmental Kuznets curve. Ecol. Econ., 29: 89-109.

DOI: $10.1016 / \mathrm{S} 0921-8009(98) 00062-7$

Murray, C.J.L., T. Vos, R. Lozano, M. Naghavi and A.D. Flaxman et al., 2012. Disability-adjusted life years (DALYs) for 291 diseases and injuries in 21 regions, 1990-2010: A systematic analysis for the global burden of disease study 2010. Lancet, 380 : 2197-2223. DOI: 10.1016/S0140-6736(12)61689-4

Murty, M.N. and S. Kumar, 2002. Measuring the cost of environmentally sustainable industrial development in India: A distance function approach. Environ. Dev. Econ., 7: 467-486.

DOI: $10.1017 / \mathrm{S} 1355770 \mathrm{X} 02000281$

Nguyen, H.X., C. Chu, H.L.T. Nguyen, H.T. Nguyen and C.M. Do et al., 2017. Temporal and spatial analysis of hand, foot and mouth disease in relation to climate factors: A study in the Mekong Delta region, Vietnam. Sci. Total Environ., 581-582: 766-772. DOI: $10.1016 /$ j.scitotenv.2017.01.006

Nichols, G., C. Lane, N. Asgari, N.Q. Verlander and A. Charlett, 2009. Rainfall and outbreaks of drinking water related disease and in England and Wales. 2001: 1-8.

Oiamo, T.H., 2014. Environmental health effects of multiple exposures: Systemic risks and the detroit river international crossing study. $\mathrm{PhD}$ Thesis of Philosophy, The School of Graduate and Postdoctoral Studies, The University of Western Ontario, London, Ontario, Canada.
Oppenheimer, M., M. Campos, R. Warren, J. Birkmann and G. Luber et al., 2015. Emergent risks and key vulnerabilities. Climate Chang 2014 Impacts, Adapt Vulnerability Part A Glob Sect Asp, pp: 1039-1100.

Ostfeld, R.S., 2017. Biodiversity loss and the ecology of infectious disease. Lancet Planet Health, 1: e2-e3.

Pant, D.K., T. Tenzin, R. Chand, S.B. Kumar and B.P. Raj, 2017. Spatio-temporal epidemiology of Japanese encephalitis in Nepal, 2007-2015. PLoS One, 12: 2007-2015.

DOI: 10.1371 /journal.pone.0180591

Pant, K.P., 2008. Estimating health benefits when behaviors are endogenous: A case of indoor air pollution in rural Nepal.

Pant, K.P., 2012. Cheaper fuel and higher health costs among the poor in rural Nepal. AMBIO, 41: 271-283. DOI: $10.1007 / \mathrm{s} 13280-011-0189-6$

Patz, J.A., P.R. Epstein, T.A. Burke and J.M. Balbus, 1996. Global climate change and emerging infectious diseases. JAMA, 275: 217-223. DOI: $10.1001 /$ jama.1996.03530270057032

Patz, J.A., W.J. Martens, D.A. Focks and T.H. Jetten, 1998. Dengue fever epidemic potential as projected by general circulation models of global climate change. Environ. Health Perspect., 106: 147-153.

DOI: $10.1289 / \mathrm{ehp} .98106147$

Phung, D., C. Chu, S. Rutherford, H. Lien and T. Nguyen et al., 2016. Heavy rainfall and risk of infectious intestinal diseases in the most populous city in Vietnam. Sci. Total Environ., 580: 805-812. DOI: $10.1016 /$ j.scitotenv.2016.12.027

Podesta, J. and P. Ogden, 2008. The security implications of climate change. J. Washington Quarterly, 31: 115-138.

DOI: 10.1162/wash.2007.31.1.115

Pokhrel, D. and T. Viraraghavan, 2005. Municipal solid waste management in Nepal: Practices and challenges. Waste Manage., 25: 555-562. DOI: 10.1016/j.wasman.2005.01.020

Prüss-Ustün, A., J. Wolf, C.R. Corvalán and R.N.M. Bos, 2016. Preventing disease through healthy environments: a global assessment of the burden of disease from environmental risks.

Prüss-Üstün, A., R. Bos, F. Gore and J. Bartram, 2008. Safer Water, Better Health. 1st Edn., World Heal Organ, pp: 53.

Sattenspiel, L., 2000. Tropical environments, human activities and the transmission of infectious diseases. Am. J. Phys. Anthropol., 31: 3-31.

Sheffield, P.E. and P.J. Landrigan, 2011. Global climate change and children's health: Threats and strategies for prevention. Environ. Health Perspect., 119: 291-298. DOI: 10.1289/ehp.1002233

Shim, C., J. Seo, J. Han, J. Ha and T.H. Ro et al., 2017. Projection of future hot weather events and potential population exposure to this in South Korea. Climate Res., 72: 29-38. DOI: 10.3354/cr01446 
Shope, R., 1991. Global climate change and infectious diseases. Environ. Health Perspect., 96: 171-174. DOI: 10.1289/ehp.9196171

Shrestha, S.L., I.L. Shrestha, N. Shrestha and R.D. Joshi, 2017. Statistical modeling of health effects on climate-sensitive variables and assessment of environmental burden of diseases attributable to climate change in Nepal. Environ. Model Assess., 22: 459-472. DOI: 10.1007/s10666-017-9547-5

Singh, A., C.N. Kesavachandran, R. Kamal, V. Bihari and A. Ansari et al., 2017. Indoor air pollution and its association with poor lung function, microalbuminuria and variations in blood pressure among kitchen workers in India: A cross-sectional study. Environ. Health, 16: 1-13.

DOI: 10.1186/s12940-017-0243-3

Singh, R.B., S. Hales, N. de Wet, R. Raj and M. Hearnden et al., 2001. The influence of climate variation and change on diarrheal disease in the pacific Islands. Environ. Health Perspect., 109: 155-159.

Speldewinde, P.C., A. Cook, P. Davies and P. Weinstein, 2009. A relationship between environmental degradation and mental health in rural Western Australia. Health Place, 15: 880-887.

DOI: $10.1016 /$ j.healthplace.2009.02.011

Srimath-Tirumula-Peddinti, R.C.P.K., N.R.R. Neelapu and N. Sidagam, 2015. Association of climatic variability, vector population and malarial disease in district of Visakhapatnam, India: A modeling and prediction analysis. PLoS One, 10: 1-30.

DOI: 10.1371 /journal.pone.0128377

Stephen, D.M. and A.G. Barnett, 2017. Using microsimulation to estimate the future health and economic costs of salmonellosis under climate change in central Queensland, Australia. Environ. Health Perspect.

Sutherst, R., 1998. Implications of global change and climate variability for vector-borne diseases: Generic approaches to impact assessments. Int. J. Parasitol., 28: 935-945. DOI: $10.1016 / \mathrm{S} 0020-7519(98) 00056-3$

Terzopoulou, E. and D. Voutsa, 2017. Study of persistent toxic pollutants in a river basinecotoxicological risk assessment. Ecotoxicology, 26: 625-638. DOI: 10.1007/s10646-017-1795-2

Tin, T.S., A. Woodward, R. Saraf, S. Berry and C.P. Atatoa et al., 2016. Internal living environment and respiratory disease in children: Findings from the Growing Up in New Zealand longitudinal child cohort study. Environ. Health, 15: 1-10. DOI: $10.1186 / \mathrm{s} 12940-016-0207-\mathrm{z}$

Tiwari, S., H.G. Jacoby and E. Skoufias, 2017. Monsoon babies: Rainfall shocks and child nutrition in Nepal. Econ. Dev. Culture Change, 65: 167-188.

DOI: $10.1086 / 689308$
Tjaden, N.B., J.E. Suk, D. Fischer, S.M. Thomas and C. Beierkuhnlein et al., 2017. Modelling the effects of global climate change on Chikungunya transmission in the 21st century. Sci. Rep., 7: 1-11. DOI: $10.1038 / \mathrm{s} 41598-017-03566-3$

Tol, R.J.S., 2002. Estimates of the damage costs of climate change, Parts II. Dynamic Estimates. Environ. Resource Econ., 21: 135-160. DOI: $10.1023 / \mathrm{A}: 1014539414591$

TWB, 2010. The costs to developing countries of adapting to climate change. The World Bank.

UNFCCC, 2009. Potential costs and benefits of adaptation options: A review of existing literature. Development, United Nations Framework Convention on Climate Change.

Unit, S.D., S.A. Region and W. Bank, 2001. Priorities in Andhra Pradesh. South Asia.

WHO, 2009a. Global health risks. World Health Organization.

WHO, 2009b. Protecting health from climate change: Global research priorities. WHO.

WHO, 2014. Preventing Diarrhoea Through Better Water, Sanitation and Hygiene: Exposures and Impacts in Low-and Middle-Income Countries. 1st Edn., WHO Libr Cat Data, pp: 48.

WHO, 2016a. The Public Health Impact of Chemicals: Knowns and Unknowns. International Programme on Chemical Safety, World Health Organization Press, Avenue Appia, Geneva, Switzerland.

WHO, 2016b. Protecting Surface Water For Health Identifying, Assessing and Managing DrinkingWater Quality Risks in Surface-Water Catchments. 1st Edn., World Health Organization, ISBN-10: 9789241510554, pp: 196.

WHO, 2016c. World health statistics - monitoring health for the SDGs. World Heal Organization.

WHO, 2017a. South-East Asia. 6: 1-98.

WHO, 2017b. World Health Statistics 2017: Monitoring Health for The SDGs. 1st Edn., World Health Organization, pp: 103.

Wiwanitkit, S. and V. Wiwanitkit, 2013. Short communication ckikungunya virus infection and relationship to rainfall, the rela- tionship study from Southern Thailand. 7: 185-187.

Wolf, J., S. Bonjour and A. Prüss-Ustün, 2013. An exploration of multilevel modeling for estimating access to drinking-water and sanitation. J. Water Health, 11: 64-77. DOI: 10.2166/wh.2012.107

Wu, P.C., H.R. Guo, S.C. Lung, C.Y. Lin and H.J. Su, 2007. Weather as an effective predictor for occurrence of dengue fever in Taiwan. Acta Trop., 1031: 50-57.

DOI: 10.1016/j.actatropica.2007.05.014 
Wu, P.C., J.G. Lay, H.R. Guo, C.Y. Lin and S.C. Lung et al., 2009. Higher temperature and urbanization affect the spatial patterns of dengue fever transmission in subtropical Taiwan. Sci. Total Environ., 407: 2224-2233.

DOI: $10.1016 /$ j.scitotenv.2008.11.034

Yoon, S.J., I.H. Oh, H.Y. Seo and E.J. Kim, 2014. Measuring the burden of disease due to climate change and developing a forecast model in South Korea. Public Health, 128: 725-733.

DOI: $10.1016 /$ j.puhe.2014.06.008

Young, H.S., C.L. Wood, A.M. Kilpatrick, K.D. Lafferty and C.L. Nunn et al., 2017. Conservation, biodiversity and infectious disease: Scientific evidence and policy implications. Philosophical. Trans. R Soc. B Biol. Sci., 372: 1-4.

DOI: $10.1098 /$ rstb.2016.0124
Zuckerman, J.N., 2012. Infectious Diseases: A Geographic Guide. In: Travel Medicine and Infectious Disease, Schlagenhauf-Lawlor, P. (Ed.), Elsevier B.V.

Zurbrugg, C. and S. Eawag, 2013. Solid waste management in developing countries. Challenges.
Abbreviations
AUD Australian Dollar
DALYs Disability Adjustment Life Years
GCM General Circulation Model
GDP Gross Domestic Product
QALYS Quality Adjustment Life Years
SDGs Sustainable Development Goals
UK United Kingdom
USA United States of America
VBD Vector Borne Disease
WHO World Health Organization 